\title{
Correction: Updated staging and patient outcomes in low-grade appendiceal mucinous neoplasms
}

\author{
Samuel J. Ballentine - Jacquelyn Carr • Eliahu Y. Bekhor · Umut Sarpel · Alexandros D. Polydorides (D)
}

Published online: 3 May 2021

(c) The Author(s), under exclusive licence to United States \& Canadian Academy of Pathology 2021

Correction to: Modern Pathology

https://doi.org/10.1038/s41379-020-0628-7

The original version of this article unfortunately contained a mistake. There was a typographical error in Table 3. The acronym for cytoreduction completeness score should be CCS. The authors apologize for the mistake. The original article has been corrected. 